\title{
A Psychometric Analysis of the High Potential Trait Inventory (HPTI)
}

\author{
Ian MacRae1, Adrian Furnham ${ }^{2 *}$ \\ ${ }^{1}$ Research Department of Clinical, Educational and Health Psychology, University College London, London, UK \\ ${ }^{2}$ Norwegian Business School (BI), Nydalveien, Olso, Norway \\ Email: *adrian@adfrianfurnham.com
}

How to cite this paper: MacRae, I., \& Furnham, A. (2020). A Psychometric Analysis of the High Potential Trait Inventory (HPTI). Psychology, 11, 1125-1140. https://doi.org/10.4236/psych.2020.118074

Received: February 29, 2020

Accepted: August 16, 2020

Published: August 19, 2020

Copyright (C) 2020 by author(s) and Scientific Research Publishing Inc. This work is licensed under the Creative Commons Attribution International License (CC BY 4.0).

http://creativecommons.org/licenses/by/4.0/ (c) (i) Open Access

\begin{abstract}
This study aimed to investigated the psychometric properties of the High Potential Traits Inventory (HPTI), particularly reliability, structure as well as convergent and predictive validity. The previously established six-factor structure (MacRae \& Furnham, 2014) was tested through structural equation modelling (SEM), along with subscale reliabilities measured by Cronbach's $\alpha$. All subscales had high reliability. Convergent validity with the NEO-PI-R was also tested. All HPTI and NEO-PI-R personality factors were regressed on a measure of subjective success to determine predictive validity. Model fit was sufficient for early scale validation, but suggested more work needs to be done. HPTI subscales were highly correlated with subjective success, and significantly better predictors of subjective success when all personality factors were regressed on a measure of subjective success. Limitations, implications, and the need for further work are discussed.
\end{abstract}

\section{Keywords}

Talent, Potential, Traits, Conscientiousness, Competitiveness, Adjustment

\section{Introduction}

The idea of High-Flying individuals, namely those with a high potential or high probability of success in their careers, was first explored qualitatively (Hermans, 2007; McCall, 1997; 2010). McCall indicated that high-flyers are those with a high potential to progress to senior leadership positions. High-Flyers or those with "High Potential" are often described as talented individuals whose combinations of abilities, personality, and motivation patterns mean that they are very successful at work, as measured by early promotions, ratings by others, income, and perceived contribution to overall organisational success. However, there 
have been few systematic or empirical attempts at the validation of high-flying traits, specifically in the workplace (McCall, 1997; 2010).

Definitions and outcome measures vary widely between studies. The term potential is regularly in the literature, but typically appears as a vague, amorphous term that does not identify specific outcomes or end-states (Silzer \& Church, 2009). Furthermore, most research uses past success as an outcome measure (Fuller \& Marler, 2009; Barrick, Mount \& Judge, 2001); which a useful indicator of potential in the workplace, past success is insufficient to generalise to future performance or outcomes. There is a scattered literature on personality and occupational success which suggests that some personality traits are consistently and explicably related to both subjective and objective measures of work outcome and success, albeit with the modest correlations (Furnham, 2017).

Spreitzer, McCall, and Mahoney (1997) suggested the ability to learn from experience is a major contributor to executive success, but the proposed measure was difficult to reconcile with current models of personality such as the Five Factor Model (FFM; Barrick, et al., 2001). Spreitzer and colleagues proposed a 14-factor model with a great deal of overlap between the proposed dimensions which were often described in "lay" rather than psychological concepts. For example, they propose "Open to Criticism" and "Seeks Feedback" as two separate factors, while not distinguishing between the two. Furthermore, they tested the factorial structure of their proposed 14-factor model but failed to investigate whether there are more parsimonious factorial structures to fit their data.

The FFM is also a widely used and valid measure of personality, however, it is not designed specifically for applied use in the workplace. The same is true of other general measures of "bright-side" as well as "dark-side" personality (Hogan, Hogan, \& Warrenfeltz, 2007). Problems with using general measures of personality at either the domain or facet level are that they often measure variables that are not relevant to work success while neglecting those that are (Hough \& Furnham, 2003). We set out to devise a parsimonious, validated, work-related measure of high potential as measured by various indices of success at work.

We propose personality is an adaptive cognitive mechanism which promotes or inhibits searching for opportunities, dedication to tasks and subsequent emotions associated with success or failure in completing tasks. We suggest a model of personality would have the most utility for work psychologists if validated based on work- and career-related outcome variables. Thus, a model of high potential traits that helps to explain the stable individual differences associated with performance and potential at work (MacRae \& Furnham, 2014).

\subsection{Theoretical Framework to Measure High Potential}

Organisations require the tools and processes to identify and to recruit high po- 
tential individuals (McDonnell et al., 2010). A major challenge for employers is to identify and measure potential to be effective in future roles, particularly over years and decades (Silzer \& Church, 2009). The current literature has developed the idea of High-Flyers (McCall, 1997) and investigated correlates of performance (Fuller \& Marler, 2009).

The measurement of personality is currently dominated by the FFM of personality. The best measure of the FFM is the NEO-PI-R (Costa \& McCrae, 1992), however it is too lengthy and time-consuming for many researchers and for applied use in workplaces (Muck, Hell \& Gosling, 2007). Furthermore, much of the current research and literature does not provide the tools or strong conceptual models necessary to address the needs of applied workplace psychology (McDonnell, 2011) and is only descriptive of statistic findings without providing explanations about personality within the "system" of interconnections with other variables to create an adaptive system (Block, 2010).

Current measures of personality have been modestly related to career success, but the specific relationship with career success and achievement requires further investigation. Costa and McCrae (1992) found Conscientiousness, Neuroticism and Openness are predictive of career success. Ng, Eby, Sorensen and Feldman (2005) also found modest associations between personality traits and career success in a meta-analysis. Linden, Nijenhuis, and Bakker (2010) found correlations between Openness, Adjustment, and performance in a meta-analysis of 212 studies $(N=144,117)$. McCall (1997) conducted extensive qualitative research and proposed characteristics associated with High-Flyers including courage, opportunity seeking, and adaptation to cultural differences. Learning from experience (McCall, 1997; 2010) is an important component, but it is insufficient to fully understand high potential and is not helpful for early identification of those likely to be moderately or highly successful in the workplace. Silzer and Church (2009) suggest a clear construct of potential is required but does not exist in the current literature. For the purpose of this research, potential in the context of work is defined as the ability to survive and thrive in the labour market demands and opportunities of time.

Silzer and Church (2009) proposed three dimensions of potential: foundational, growth, and career dimensions. Growth dimensions are relatively stable characteristics that are moderated by states and drives such as motivation and ambition. Career dimensions are influenced by context and are dependent on the particular career and occupation. Performance and knowledge are career dimensions and are primarily constrained within specific occupations.

Career dimensions are too occupation- or position-specific for a general measure of potential; growth and foundational dimensions of potential lend themselves to a generalisable measure such as the High Potential Traits Indicator. Foundational and growth dimensions of potential may include personality because personality can directly and indirectly affect performance (Barrick, Mount, \& Judge, 2001; Dragoni, Oh, Vankatwyk, \& Tesluk, 2011; Linden et al., 2010). Furnham, Crump and Chamorro-Premuzic (2007) found signifi- 
cant personality differences between non-managers and managers. Managers' report higher need for control, higher need for recognition, and higher diligence. Individuals high on the Openness personality trait welcome new ideas, and new ways of doing and thinking. Those with high Conscientiousness are more discerning, more focused on planning and controlling their own behaviour and act dutifully. Hannah, Sweeney and Lester (2007) suggest courage is a personality trait that broadens an individual's potential range of responses when faced with aversive stimuli.

Most research compares the well-validated Big Five personality model with measures of performance (Barrick et al., 2001; Linden et al., 2010), but organisations and recruiters are most interested in measures that are specifically tailored for identifying potential; the Big Five has extraneous factors that are not associated with workplace performance or potential (McDonnell, 2011). Silzer and Church (2009) provide a strong theoretical model that includes a range of interconnected variables, as well as providing an explanation of how and why different variables contribute to adaptive (or maladaptive) behaviour at work.

The development of the High Potential Traits Indicator and model began with a literature review which attempted to identify all the unique, if related, traits that have been shown to be related to success at work broadly defined. This yielded a list of 15 traits which, once examined for conceptual overlap, was reduced to ten. A 120 item (12 items per trait) measure was then constructed and administered to 450 adults (Dissou, 2003). This research was continued by MacRae (2012) who worked to develop a measure of personality for applied use at work, and developed a model of six clear and interpretable factors, the High Potential Traits Inventory (HPTI). Each of the six traits was hypothesized to be highly related to subjective success at work. Various studies have been done using this measure (Teodorescu, Furnham, \& MacRae, 2017; Furnham \& Treglown, 2018).

\subsection{High Potential Traits Inventory}

\subsubsection{Conscientiousness}

Conscientiousness is a FFM personality trait that is characterised by self-discipline, organisation, and ability to moderate one's own impulses (Costa \& McCrae, 1992, Wille et al., 2013). In a review of major measures of personality Jackson et al. (2009) confirmed conscientiousness is a higher-order factor composed of six underlying facets: industriousness, order, self-control, responsibility, traditionalism, and virtue. Judge, Martocchio and Thoresen (1997) found conscientiousness was a predictor of lower employee absence from a demographically representative group of 89 non-academic employees at an American university. Barrick et al.'s (2001) meta-analysis found conscientiousness was a moderate predictor of job success across all jobs and all measures of success. Furthermore, conscientiousness is relatively stable across time, but aspects of conscientiousness such as impulse control, reliability, and conventionality can increase with 
age (Jackson et al., 2009).

\subsubsection{Adjustment}

Adjustment is the adaptive end of the FFM neuroticism trait (Costa \& McCrae, 1992; Wille et al., 2013) characterised by recurrent emotional resilience to stressors, positive affect, and perceptions. Adjustment has been linked to higher performance. Judge \& Locke (1992) found neuroticism (low adjustment) was associated with lower subjective well-being and job satisfaction. Barrick et al.'s (2003) meta-analysis found higher adjustment was associated with improved performance and better teamwork in many occupations.

\subsubsection{Curiosity}

Curiosity (openness) is a Big Five personality trait characterised by curiosity for new ideas, experiences and situations. Openness at work encompasses new ways of completing tasks, new business ideas, and interest in colleagues with different opinions. Openness includes elements of reflectiveness, creativity and innovation. Judge, Higgins, Thoreson, and Barrick (1999) conducted an analysis from three American longitudinal studies with 530 participants and found openness was moderately associated with job satisfaction, occupational status, and extrinsic career success. Linden et al. (2010) confirmed openness was associated with improved performance and learning outcomes. Barrick et al.'s (2003) meta-analysis of personality and job performance found openness was moderately associated with training proficiency, but it was less related to performance than conscientiousness or adjustment.

\subsubsection{Ambiguity Acceptance}

Ambiguity Acceptance, sometimes described as Ambiguity Tolerance (AT), describes how an individual or group processes and perceives unfamiliarity or incongruence (Furnham \& Ribchester, 1995). Those who are tolerant of ambiguity perform well in new or uncertain situations, adapt when duties or objectives are unclear, and are able to learn in unpredictable times or environments (Furnham, 1994). McCall (1997) suggested from extensive qualitative evidence that adapting to ambiguity is an essential trait of High-Flyers. Herman et al. (2010) found ambiguity tolerance involved four facets: valuing diversity, challenging perspectives, unfamiliarity, and change. The ambiguity tolerance component of the High Potential Traits Indicator Traits incorporates these four facets. Keenan and McBain (2011) found high AT reduced psychological strain in positions that involved role ambiguity. Those with higher ambiguity tolerance should perform better in high-level leadership positions because they have to incorporate many different sources of information and make decisions based on mixed information.

\subsubsection{Competitiveness}

Wang and Netemeyer (2002) propose competitiveness is a distinct trait that reflects part of McClelland's (1965) N-Ach, and the achievement component of 
Type A personality (Thornton et al., 2011). Trait competitiveness focuses on the adaptive elements of competitiveness that drive self-improvement, desire for individual and team success, and learning. Wang and Netemeyer (2002) studied the determinants of performance with 147 salespeople in the United States. They found competitiveness, mediated by learning effort, was a significant predictor of sales performance. Thus, competitiveness can be an important factor in High Potential Traits Indicator. Competitiveness may be a growth dimension that indicates a High-Flying potential, but unlike traits such as conscientiousness, may not lead directly to improved performance.

\subsubsection{Courage}

Courage is the ability to combat or mitigate negative or threat-based emotions and broaden the potential range of responses. Fredrickson's (2001) broaden and build theory of positive psychology proposes that negative emotions restrict an individual's potential range of actions by creating overwhelming impulses to act in a certain way. Fear may create a strong drive to avoid the offending stimulus and restrict the perceived range of responses. Hannah et al. (2007) suggest the courageous individual uses the positive emotion, courage, to mitigate fear of interpersonal conflict or reprisal to confront the behaviour. In an empirical study, Norton \& Weiss (2009) found self-report measures of courage predicted actual courageous responses in a fear-evoking situation. Unchecked fear restricts the potential range of responses and typically leads to behaviours like avoidance or contrived ignorance. Whereas courage is exhibited as the willingness to confront difficult situations and solve problems in spite of adversity. Therefore, courage can be expressed in many situations including calculated risk taking, interpersonal confrontation, problem solving, or moral fortitude. However, all these courageous behaviours have the same underlying cognitive mechanism of broadening the range of potential responses (Norton \& Weiss, 2009).

In this study we predict that all HPTI traits will be significantly correlated with subjective success.

Further, the senior managers will have significantly higher levels of HPTI traits than managers.

\section{Method}

\subsection{Participants}

The participants were drawn from three separate samples who participated in HPTI research done by both authors between 2014 and 2018. All were volunteers and where possible given feedback. One sample was comprised of 301 participants from around the world who were required to be employed, full-time. They were tested online with the Amazon-Turk software and paid $£ 1.00$ to participate. The second sample was composed of 183 participants from an assessment center and included managers and senior managers working in multinational companies within Europe. Senior managers in this sample were head-of-company-level seniority. The third sample of 295 participants was 
composed of officers in the UK Armed Forces at the rank of major or equivalent. Table 1 details the sample sizes and the instruments administered to participants in each sample.

The overall sample was composed of 779 employed, working professionals from over 25 countries, primarily from the UK (66.8\%), Canada (10.8\%), South Africa (4.4\%), Singapore (4.4\%) and Norway (2.3\%). The sample includes 574 men and 205 women, ages ranged from 17 to 64 . The mean age was 39.46 (SD: 9.05). Respondents represented a wide range of occupations, industries and positions within the company. Main occupations represented were Business, Management and Finance (41.2\%), Armed Forces (37.9\%), and mechanical trades (8.7\%). Unpaid respondents were offered an individual profile describing their results on a personality test online to motivate them.

All participants in every sample were required to be in full time employment. Testing was conducted online. Pairwise deletion was used for missing data.

\subsection{Instruments}

\subsubsection{High-Flyers}

The 78-item High Potential Trait Inventory (HPTI) is a modification of the High Potential Traits Indicator Inventory (HFPI) based on research presented in MacRae and Furnham (2014), and MacRae (2012). Participants rate their agreement with statements about their thoughts, feelings, behaviours, and others' perceptions of them at work, using a 7-point Likert scale anchored with Strongly Agree and Strongly Disagree at opposing ends. In previous studies (MacRae, 2012) the initial development of the HFPI was based on a 101-item questionnaire with items distributed equally on 9 hypothesized scales, designed to measure a variation of McCall's dimensions of High-Flyers. The factorial structure was tested with a group of 461 working professionals and revised to improve the parsimony of the factor structure. An improved, 6-factor structure was suggested based on the results, and 53 of the original HFPI items were retained, and 25 added based on pilot work.

\subsubsection{NEO Personality Inventory Form S (NEO-PI-R; McCrae, \& Costa, 1985)}

The NEO is a five factor measures of the personality traits Openness to

Table 1. Overview of samples and instruments used.

\begin{tabular}{ccccc}
\hline & $\begin{array}{c}\text { International } \\
\text { Professionals } \\
(\mathrm{N}=301)\end{array}$ & $\begin{array}{c}\text { European } \\
\text { Managers } \\
(\mathrm{N}=183)\end{array}$ & $\begin{array}{c}\text { UK Armed Forces } \\
(\mathrm{N}=295)\end{array}$ & $\begin{array}{c}\text { Sample Size of } \\
\text { each Instrument }\end{array}$ \\
\hline HPTI & $\checkmark$ & $\checkmark$ & $\checkmark$ & 779 \\
FFM & $\checkmark$ & $\checkmark$ & 295 \\
Subjective Success & $\checkmark$ & $\checkmark$ & $\checkmark$ & 779 \\
Managerial Level & & $\checkmark$ & & 183 \\
\hline
\end{tabular}


Experience, Conscientiousness, Extraversion, Agreeableness, and Neuroticism. The NEO-PI-R responds using a 5-point Likert scale to rate their agreement with 240 self-descriptive statements anchored between strongly agree and strongly disagree.

\subsubsection{Subjective Success}

Participants were asked to rate their own success at work, on a 7-point Likert scale anchored at Strongly Disagree to Strongly Agree "I am very successful in my line of work". This can be interpreted as an indicator of Silzer \& Church's (2009) foundational potential because it relates to general performance which is not task or occupation specific. Responses ranged from 1 to $7(M=5.28, \mathrm{SD}=$ 1.09. It was used in the study by Teodorescu et al. (2017) and shows a normal distribution.

\subsection{Procedure}

All participants completed the study online. All three groups were contacted by the two authors and an explanation for the study given. All received a full report on their results. The response rate was around $70 \%$. Where participants wanted clarification of their results, these were provided. Before the test was administration was done, departmental ethics permission was sought and received.

\section{Results}

\subsection{Descriptive Statistics}

Table 2 shows descriptive statistics and alpha values for each of the subscales. All subscales have acceptable alpha levels (greater than 0.70 for initial scale development) indicating sufficient reliability (Yang \& Green, 2011).

Women had slightly higher HPTI conscientiousness, curiosity, and courage in the samples, although the effect size was small. Consistent with previous findings (Chapman, Duberstein, Sorensen, \& Lyness, 2008; Hyde, 2005) women had much higher neuroticism scores on the NEO inventory than men, with a large effect size (shown in Table 3).

\subsection{Six Factor Model Fit}

Conscientiousness, ambiguity acceptance, and courage all had acceptable SRMR

Table 2. Descriptive statistics and alpha values for HPTI sub-scales (all samples).

\begin{tabular}{ccccccc}
\hline & Items & Min & Max & Mean & SD & $\alpha$ \\
\hline Conscientiousness & 13 & 37 & 90 & 71.43 & 8.62 & 0.77 \\
Adjustment & 13 & 19 & 78 & 53.39 & 9.97 & 0.78 \\
Curiosity & 13 & 31 & 84 & 64.83 & 8.08 & 0.80 \\
Ambiguity & 13 & 28 & 85 & 56.21 & 9.08 & 0.74 \\
Courage & 13 & 36 & 87 & 64.99 & 8.78 & 0.72 \\
Competitiveness & 13 & 20 & 87 & 53.92 & 10.34 & 0.74 \\
\hline
\end{tabular}


Table 3. Gender differences between HPTI and NEO scales.

\begin{tabular}{|c|c|c|c|c|c|c|c|c|c|c|c|}
\hline \multirow{2}{*}{ Scale } & \multirow{2}{*}{ Items } & \multicolumn{3}{|c|}{ Male } & \multicolumn{3}{|c|}{ Female } & \multirow{2}{*}{$\mathrm{t}$-test } & \multirow{2}{*}{ Cohen's d } & \multicolumn{2}{|c|}{$A 11$} \\
\hline & & $\mathrm{N}$ & $M$ & $S D$ & $\mathbf{N}$ & $M$ & $S D$ & & & Kurtosis & Skew \\
\hline$H P T I$ & 78 & & & & & & & & & & \\
\hline Conscientiousness & 13 & 545 & 71.07 & 8.39 & 198 & 72.63 & 9.09 & $2.20^{*}$ & -0.18 & -0.44 & 0.01 \\
\hline Adjustment & 13 & 555 & 53.33 & 9.73 & 200 & 53.55 & 10.39 & 0.31 & -0.02 & -0.3 & 0.13 \\
\hline Curiosity & 13 & 563 & 64.18 & 8.09 & 202 & 66.65 & 7.77 & $3.76^{* * *}$ & -0.31 & -0.11 & -0.27 \\
\hline Ambiguity & 13 & 549 & 56.18 & 9.19 & 201 & 56.24 & 8.80 & 0.08 & -0.01 & 0.15 & -0.03 \\
\hline Courage & 13 & 557 & 65.54 & 8.67 & 201 & 63.48 & 9.02 & $2.86^{\star}$ & 0.23 & -0.07 & -0.06 \\
\hline Competitiveness & 13 & 561 & 54.29 & 10.19 & 200 & 52.88 & 10.79 & 1.65 & 0.13 & -0.21 & 0.08 \\
\hline$N E O$ & 60 & & & & & & & & & & \\
\hline Neuroticism & 12 & 234 & 36.07 & 7.08 & 49 & 41.02 & 7.41 & $4.41^{* * *}$ & -0.68 & 0.25 & -0.05 \\
\hline Extraversion & 12 & 227 & 51.33 & 5.27 & 50 & 51.82 & 5.95 & 0.58 & -0.09 & -0.30 & 0.10 \\
\hline Openness & 12 & 232 & 50.44 & 5.09 & 49 & 51.18 & 4.60 & 1.67 & -0.15 & 0.04 & -0.18 \\
\hline Agreeableness & 12 & 235 & 56.31 & 4.67 & 49 & 57.39 & 5.03 & 1.45 & -0.19 & -0.24 & -0.14 \\
\hline Conscientiousness & 12 & 244 & 54.89 & 6.03 & 49 & 55.94 & 6.75 & 1.09 & -0.16 & -0.79 & 1.18 \\
\hline
\end{tabular}

Note: ${ }^{\star} p<0.05 ;{ }^{* *} p<0.01 ;{ }^{* *} p<0.001$.

values, and the other three sub-scales had levels approaching acceptable levels (see Table 4) SRMR values lower than 0.08 is considered good fit (Hu \& Bentler, 1999), 0.5 for RMSEA, greater than 0.95 for CFI. Cutoff value close to 0.08 for RMSEA and 0.06 for SRMR. Cutoff RMSEA values up to 0.10 have been deemed acceptable; although more recent cut-off guidelines have been proposed at 0.08 or 0.07 (Hooper et al., 2008), this is not necessary for an early validation. All sub-scale SRMR values are below 0.08 in this study. CFI values for all sub-scales do not yet reach the recommended CFI values.

\subsection{Convergent Validity (NEO Scales Correlation)}

Pearson correlations were used to explore the relationship between HPTI and NEO (see Table 5 and Table 6) While the HPTI was included in all samples, only the Armed Forces $(N=295)$ sample included both the HPTI and NEO. Pairwise deletion was used in this analysis. As would be expected: HPTI Conscientiousness was significantly positively correlated with NEO Conscientiousness; HPTI Curiosity was significantly positively correlated with NEO Openness; and HPTI Adjustment was significantly negatively correlated with NEO Neuroticism. This shows encouraging convergent validity between HPTI and NEO variables that would be expected to show convergent validity. There were many other significant correlations between variables consistent with previous research in personality psychology.

\subsection{Regression with Subjective Work Success}

This was followed by regressions. First, two regression analyses were performed, 
Table 4. SEM model fit for HPTI sub-scales from (all samples).

\begin{tabular}{ccccccccc}
\hline Scale & $\chi^{2}$ & d.f. & $\chi^{2} /$ d.f. & CFI & RMSEA & $90 \%$ CI & $\begin{array}{c}\text { p value } \\
\text { RMSR }\end{array}$ & SRMR \\
\hline Conscientiousness & 440 & 65 & 6.77 & 0.805 & 0.087 & $0.080-0.095$ & 0.000 & 0.061 \\
Ambiguity & 256 & 65 & 3.94 & 0.876 & 0.062 & $0.054-0.070$ & 0.006 & 0.047 \\
Courage & 346 & 65 & 5.32 & 0.764 & 0.075 & $0.067-0.717$ & 0.000 & 0.060 \\
Adjustment & 570 & 65 & 8.77 & 0.735 & 0.101 & $0.093-0.108$ & 0.000 & 0.070 \\
Curiosity & 667 & 65 & 10.26 & 0.727 & 0.109 & $0.102-0.117$ & 0.000 & 0.078 \\
Competitiveness & 481 & 65 & 7.40 & 0.732 & 0.091 & $0.084-0.099$ & 0.000 & 0.068 \\
\hline
\end{tabular}

Note: $\chi^{2}$, chi square; d.f., degrees of freedom; CFI, comparative fit index; TLI, RMSEA, root mean square error of approximation, 90 .

Table 5. Scale intercorrelations (HPTI all samples, NEO Armed Forces sample).

\begin{tabular}{|c|c|c|c|c|c|}
\hline & $\begin{array}{c}N E O \\
N\end{array}$ & $\begin{array}{c}N E O \\
E\end{array}$ & $\begin{array}{c}N E O \\
O\end{array}$ & $\begin{array}{c}N E O \\
A\end{array}$ & $\begin{array}{c}N E O \\
C\end{array}$ \\
\hline HPTI Adjustment & $-0.64^{\star * *}$ & $0.37^{\star * *}$ & 0.09 & $0.45^{\star * *}$ & $0.38^{* * *}$ \\
\hline HPTI Courage & $-0.52^{\star * *}$ & $0.40^{* * *}$ & 0.04 & 0.10 & $0.38^{\star * *}$ \\
\hline HPTI Competitiveness & $-0.23^{\star * *}$ & $0.26^{\star * *}$ & -0.08 & $-0.22^{\star * *}$ & $0.13^{\star}$ \\
\hline HPTI Ambiguity & $-0.46^{\star * *}$ & $0.22^{* * *}$ & $0.27^{\star \star *}$ & $0.13^{*}$ & 0.11 \\
\hline HPTI Curiosity & $-0.19^{\star *}$ & $0.33^{\star * *}$ & $0.46^{* * *}$ & $0.22^{\star * *}$ & $0.18^{\star}$ \\
\hline HPTI Conscientiousness & $-0.40^{* * *}$ & $0.36^{* * *}$ & 0.02 & $0.18^{*}$ & $0.70^{* * *}$ \\
\hline
\end{tabular}

Note: ${ }^{*} p<0.05 ;{ }^{* *} p<0.01 ;{ }^{* *} p<0.001$.

Table 6. Correlations between HPTI and subjective success at work (all samples).

\begin{tabular}{|c|c|c|c|c|c|c|c|}
\hline & 1 & 2 & 3 & 4 & 5 & 6 & 7 \\
\hline 1. HPTI Adjustment & - & $0.49^{\star * *}$ & 0.00 & $0.49^{* * *}$ & $0.28^{\star * *}$ & $0.35^{\star * *}$ & $0.30^{* * *}$ \\
\hline 2. HPTI Courage & & - & $0.28^{\star * *}$ & $0.51^{* * *}$ & $0.43^{\star * *}$ & $0.54^{* * *}$ & $0.34^{* * *}$ \\
\hline 3. HPTI Competitiveness & & & - & 0.06 & $0.11^{\star *}$ & $0.30^{* * *}$ & $0.26^{* * *}$ \\
\hline 4. HPTI Ambiguity & & & & - & $0.36^{* * *}$ & $0.19^{* * *}$ & $0.21^{* * *}$ \\
\hline 5. HPTI Curiosity & & & & & - & $0.33^{* * *}$ & $0.25^{* * *}$ \\
\hline 6. HPTI Conscientiousness & & & & & & - & $0.49^{* * *}$ \\
\hline 7. Work Success & & & & & & & - \\
\hline
\end{tabular}

Table 7. Selection HPTI factors regression with subjective success (all samples).

\begin{tabular}{cccc}
\hline & $\boldsymbol{\beta}$ & $\boldsymbol{t}$ value & $\boldsymbol{p}$ value \\
\hline Conscientiousness & 0.38 & 9.00 & $<0.0001$ \\
Competitiveness & 0.17 & 4.33 & $<0.0001$ \\
Adjustment & 0.20 & 4.73 & $<0.0001$ \\
\hline
\end{tabular}


regressing FFA and HPTI traits on subjective work success. The five factor model alone explained $16 \%$ of the variance of subjective success, $R^{2}=0.16, F(5,257)$ $=11.13, p<0.001$ while the HPTI alone explained $30 \%$ of the variance in subjective success $R^{2}=0.30, F(6,471)=34.81, p<0.001$.

The HPTI predicted a significant proportion of the variance in subjective success. Furthermore, when regressing both HPTI and FFM variables on subjective success, HPTI Conscientiousness, Competitiveness and Adjustment were significant predictor of subjective success, explaining as much proportion of variance as using all HPTI predictors $R^{2}=0.30, F(6,487)=69.63, p<0.001$ (as shown in Table 7).

\subsection{Predictive Validity}

Two-tailed $t$-tests were used to compare the personality traits of managers vs. senior managers. This used a subset of the data from the dataset of European managers . Average scores of managers $(N=43)$ were compared with the scores of managers of managers (senior, strategic management $(N=108))$. There were significant differences in the personality traits of managers and senior managers for Curiosity, Ambiguity, Courage, and Competitiveness. Table 8 shows particularly large effect sizes for HPTI Curiosity, Ambiguity, Adjustment, and NEO Openness.

Table 8. Personality differences between managers and managers of managers.

\begin{tabular}{|c|c|c|c|c|c|c|c|c|}
\hline \multirow{2}{*}{ Scale } & \multicolumn{2}{|c|}{$\begin{array}{c}\text { Manager of } \\
\text { Managers }\end{array}$} & \multicolumn{2}{|c|}{ Manager } & \multirow{2}{*}{$\mathrm{t}$-test } & \multirow{2}{*}{ Cohen's d } & \multicolumn{2}{|c|}{$A l 1$} \\
\hline & $M$ & $S D$ & $M$ & $S D$ & & & Kurtosis & Skew \\
\hline \multicolumn{9}{|l|}{$H P T I$} \\
\hline Conscientiousness & 74.85 & 6.57 & 73.65 & 6.96 & 0.99 & 0.18 & -0.21 & -0.64 \\
\hline Adjustment & 58.46 & 9.43 & 56.23 & 8.73 & 1.34 & 0.25 & -0.21 & 0.53 \\
\hline Curiosity & 73.47 & 8.11 & 66.58 & 8.01 & $4.73^{\star \star \star}$ & 0.85 & -0.17 & -0.74 \\
\hline Ambiguity & 62.06 & 9.90 & 55.77 & 8.48 & $3.66^{\star * *}$ & 0.68 & 0.03 & -0.39 \\
\hline Courage & 72.51 & 7.34 & 66.12 & 7.29 & $4.84^{\star * *}$ & 0.87 & -0.16 & -0.40 \\
\hline Competitiveness & 56.31 & 10.11 & 53.02 & 10.60 & $1.78^{\star}$ & 0.32 & -0.22 & -0.40 \\
\hline \multicolumn{9}{|l|}{$N E O-P I-R I$} \\
\hline Neuroticism & 62.06 & 20.62 & 68.09 & 19.90 & 1.64 & -0.30 & 0.07 & -0.22 \\
\hline Extraversion & 131.38 & 19.09 & 122.23 & 22.91 & $2.51^{\star *}$ & 0.43 & -0.31 & 0.67 \\
\hline Openness & 123.40 & 17.54 & 110.91 & 14.96 & $4.11^{\star * \star}$ & 0.77 & -0.01 & -0.40 \\
\hline Agreeableness & 123.38 & 12.88 & 127.14 & 14.18 & 1.56 & -0.28 & 0.30 & 0.69 \\
\hline Conscientiousness & 136.44 & 16.27 & 137.26 & 13.97 & 0.29 & -0.05 & -0.35 & 0.28 \\
\hline
\end{tabular}

Note: Data from subset of general professional sample, $N=183$. 


\section{Discussion}

The findings in this study suggest the factorial structure of the HPTI is structurally sound and there are strong indicators of its predictive validity. Of course, further research will be essential to clarify exactly which traits contribute directly and indirectly to different measures of subjective and objective performance and potential. Items have not been removed in this study, because more research is required to improve the model fit without compromising predictive validity. Further research is required to make theory-based decisions about scale revision without making arbitrary decisions based on theoretical cut-off values.

Conscientiousness, Adjustment, and Competitiveness are significant predictors of general, subjective success at work. Curiosity, Ambiguity Acceptance, and Courage traits appear at significantly higher levels in senior management. The evidence from this study points strongly to all HPTI traits associated with measures of performance and success. However, it is both obvious and unsurprising that there is not a simple linear model where all six traits predict a single outcome variable. This may indicate there are core personality traits associated with success in any task or career at work and in fact, foundational potential. FFM conscientiousness and neuroticism have been consistently shown to be correlated with general measures of work performance (Barrick, et al., 2003). Whereas complementary traits such as curiosity, ambiguity acceptance, and courage may be required for specific job demands such as those of senior leadership. Also of importance to note, the effect sizes are very large for HPTI traits, while lower for FFM measures, and in many cases non-significant. This suggests the HPTI is picking up on key work-related differences inherent in trait requirements. While correlations are high between overlapping Big 5 and HPTI measures such as Conscientiousness $r(272)=0.70, p<0.001$, curiosity with openness $r(272)=$ $0.46, p<0.001$, and Adjustment with Neuroticism $r(272)=-0.64, p<0.001$ these differences in work samples clearly suggest the HPTI is tapping into the fundamental individual differences at work. Furthermore, personality differences between managers show the effect size is larger for HPTI curiosity than five-factor openness. There are high correlations within and between the HPTI and NEO personality traits, which we would expect, however, these findings indicate greater predictive validity of the HPTI for indicators of success and performance at work.

Although previous research has found significant gender differences on key personality traits such as neuroticism (Chapman et al., 2007). There were few gender differences on the HPTI, and the significant gender differences had very modest effect sizes. While HPTI adjustment is a similar construct to FFM neuroticism, the HPTI is more focused on thoughts, emotions and behaviours at work. Hyde (2005) also suggests the social context can drastically affect gender difference results, so the focus of the HPTI on thoughts and behaviour in a work context may affect this. It is also important to note, although the gender differences are statistically significant, the effect sizes indicate in applied uses the HPTI 
would not significantly favour either men or women in a hiring process, although employee selection decisions made using the NEO might.

The results of this study were similar to that of Teodorescu et al. (2017) who correlated the six HPTI traits with five subjective and three objective (e.g. income, last promotion) measures of success which were examined the item and totaled level. Nearly all correlations were significant $(0.11<r<0.30 ; \mathrm{N}=383)$. When both measures of success were combined, a stepwise regression indicated age, Conscientiousness, and Competitiveness accounted for $19.5 \%$ of the variance. They noted that they were consistent with previous findings. Further Ng et al. (2005) argued objective and subjective measures of success may be conceptually distinct as evidenced by the weak correlations between each other. Thus, these may be predicted by different factors. Ng et al. (2005) suggest personality traits may be more relevant for predicting subjective measures of success which are more strongly associated to psychological well-being and personal assessment, while human capital and demographics may be better predictors of objective measures of success. This idea remains to be tested (Furnham, 2017).

\section{Conclusion}

This study provided psychometric evidence for the HPTI: a personality measure useful for identifying talented people in the workplace. It is being used in various research studies (Furnham \& Treglown, 2018) as it promises to be an eminently useful and valid measure for identifying talented people in the workplace.

Like all others this paper had limitations. Three are particularly important. The first was not having a number of reliable objective measures of success like income, promotions, and appraisal data. The second was not having a large relatively homogeneous work sample from a single large organization. The third was not having longitudinal data to show how the traits predict over time.

Although some of the sub-scale reliability is good, and some SEM fit indices such as RMSEA and SRMR are acceptable, further work needs to be done on the scale to improve the CFI fit. The strong evidence from convergent and predictive validity indicates the scales are potentially very useful. The iterative process of scale development means repeated testing and improvement of scales, and initial scales do not always require the same rigorous, and arbitrary cut-off scores (John \& Soto, 2007). Thus, the scale should be investigated further for measures of predictive validity and adjustments may need to be made to the scale so it has a better fit with the proposed models to improve the construct validity. Further research is required to test the HPTI with additional measures of subjective and objective success to improve model fit without compromising predictive validity.

One obvious way forward would be to use Item Response Theory to test the model which is the next step in our research endeavor.

\section{Conflicts of Interest}

The authors declare no conflicts of interest regarding the publication of this paper. 


\section{References}

Barrick, M. R., Mount, M. K., \& Judge, T. A. (2001). Personality and Performance at the Beginning of the New Millennium: What Do We Know and Where Do We Go Next? International Journal of Selection and Assessment, 9, 9-30. https://doi.org/10.1111/1468-2389.00160

Block, J. (2010). The Five-Factor Framing of Personality and Beyond: Some Ruminations. Psychological Inquiry, 21, 2-25. https://doi.org/10.1080/10478401003596626

Chapman, B. P., Duberstein, P. R., Sorensen, S., \& Lyness, J. M. (2008). Gender Differences in Five Factor Model Personality Traits in an Elderly Cohort: Extension of Robust and Surprising Findings to an Older Generation. Personality and Individual Differences, 43, 1594-1603. https://doi.org/10.1016/j.paid.2007.04.028

Costa Jr., P. T., \& McCrae, R. R. (1992). Revised NEO Personality Inventory (NEO-PI-R) and NEO Five-Factor Inventory (NEO-FFI) Professional Manual. Odessa, FL: Psychological Assessment Resources.

Dissou, G. (2003). The Identification of High Flyer Traits (Unpublished Doctoral Thesis). London: University of London.

Dragoni, L., Oh, I., Vankatwyk, P., \& Tesluk, P. E. (2011). Developing Executive Leaders: The Relative Contribution of Cognitive Ability, Personality, and the Accumulation of Work Experience in Predicting Strategic Thinking Competency. Personnel Psychology, 64, 829-864. https://doi.org/10.1111/j.1744-6570.2011.01229.x

Fredrickson, B. L. (2001). The Role of Positive Emotions in Positive Psychology: The Broaden-and-Build Theory of Positive Emotions. American Psychologist, 56, 218-226. https://doi.org/10.1037/0003-066X.56.3.218

Fuller Jr., B., \& Marler, L. E. (2009). Change Driven by Nature: A Meta-Analytic Review of the Proactive Personality Literature. Journal of Vocational Behavior, 75, 329-345. https://doi.org/10.1016/j.jvb.2009.05.008

Furnham, A. (1994). A Content, Correlational and Factor Analytic Study of Four Tolerance of Ambiguity Questionnaires. Personality and Individual Differences, 16, 403-410. https://doi.org/10.1016/0191-8869(94)90066-3

Furnham, A. (2017). Personality and Occupational Success. In V. Zeigler-Hill, \& T. K. Shackelford (Eds.), The SAGE Handbook of Personality and Individual Differences. New York: Sage.

Furnham, A., \& Ribchester, T. (1995). Tolerance of Ambiguity: A Review of the Concept, Its Measurement and Applications. Current Psychology: Developmental, Learning, Personality, Social, 14, 179-199. https://doi.org/10.1007/BF02686907

Furnham, A., \& Treglown, L. (2018). High Potential Personality and Intelligence. Personality and Individual Differences, 128, 81-87. https://doi.org/10.1016/j.paid.2018.02.025

Furnham, A., Crump, J., \& Chamorro-Premuzic, T. (2007). Managerial Level, Personality and Intelligence. Journal of Managerial Psychology, 22, 805-818. https://doi.org/10.1108/02683940710837732

Hannah, S., Sweeney, P. J., \& Lester, P. B. (2007). Toward a Courageous Mindset: The Subjective act and Experience of Courage. Journal of Positive Psychology, 2, 129-135. https://doi.org/10.1080/17439760701228854

Herman, J. L., Stevens, M. J., Bird, A., Mendenhall, M., \& Oddou, G. (2010). The Tolerance for Ambiguity Scale: Towards a More Refined Measure for International Management Research. International Journal of Intercultural Relations, 34, 58-65. https://doi.org/10.1016/j.ijintrel.2009.09.004 
Hermans, J. (2007). High Potentials: A CEO Perspective. Journal of Studies in International Education, 11, 510-521. https://doi.org/10.1177/1028315307304187

Hogan, R., Hogan, J., \& Warrenfeltz, R. (2007). The Hogan Guide. Tulsa, OK: Hogan Press.

Hooper, D., Coughlan, J., \& Mullen, M. R. (2008). Structural Equation Modelling: Guidelines for Determining Model Fit. Electronic Journal of Business Research Methods, 6, 53-60. https://mural.maynoothuniversity.ie

Hough, L., \& Furnham, A. (2003). Importance and Use of Personality Measures in Work Settings. In R. D. Hackett (Ed.), Comprehensive Handbook of Psychology Vol. 12: W.Borman, D. Ilgen.

Hu, L., \& Bentler, P. M. (1999). Cut-Off Criteria for Fit Indexes in Covariance Structure Analysis. Conventional Criteria versus New Alternatives. Structural Equation Modeling, 6, 1-55. https://doi.org/10.1080/10705519909540118

Hyde, J. S. (2005). The Gender Similarities Hypothesis. American Psychologists, 60, 581-592. https://doi.org/10.1037/0003-066X.60.6.581

Jackson, J. J., Bogg, T., Walton, K. E., Wood, D., Harms, P. D., Lodi-Smith, J., Edmonds, G. W., \& Roberts, B. W. (2009). Not All Conscientiousness Scales Change Alike: A Multimethod, Multisample Study of Age Differences in the Facets of Conscientiousness. Journal of Personality and Social Psychology, 96, 446-459. https://doi.org/10.1037/a0014156

John, O. P., \& Soto, C. J. (2007). The Importance of Being Valid. Reliability and the Process of Construction Validation. In R. W. Robins, R. C. Fraley, \& R. F. Kreuger (Eds.), Handbook of Research Methods in Personality Psychology. New York: Guilford Press.

Judge, T. A., \& Locke, E. A. (1992). The Effect of Dysfunctional Thought Processes on Subjective Well-Being and Job Satisfaction. Journal of Applied Psychology, 78, 475-490. https://doi.org/10.1037/0021-9010.78.3.475

Judge, T. A., Higgins, C. A., Thoresen, C. J., \& Barrick, M. R. (1999). The Big Five Personality Traits, General Mental Ability, and Career Success across the Lifespan. Personnel Psychology, 52, 621-652. https://doi.org/10.1111/j.1744-6570.1999.tb00174.x

Judge, T. A., Martocchio, J. J., \& Thoresen, C. J. (1997). Five-Factor Model of Personality and Employee Absence. Journal of Applied Psychology, 82, 745-755. https://doi.org/10.1037/0021-9010.82.5.745

Keenan, A., \& McBain, G. D. M. (2011). Effects of Type A Behaviour, Intolerance of Ambiguity, and Locus of Control on the Relationship between Role Stress and Work-Related Outcomes. Journal of Occupational and Organizational Psychology, 52, 277-285. https://doi.org/10.1111/j.2044-8325.1979.tb00462.x

Klimoski, P. (Eds.), Industrial/Organizational Psychology. New York: Wiley \& Sons, Inc. pp. 131-169.

Linden, D., Nijenhuis, J., \& Bakker, A. B. (2010). The General Factor of Personality: A Meta-Analysis of the Big Five Intercorrelations and a Criterion-Related Validity Study. Journal of Research in Personality, 44, 315-327. https://doi.org/10.1016/j.jrp.2010.03.003

MacRae, I. (2012). Success, Potential and Validating a Measure of High Flying Personality Traits (Unpublished Master's Dissertation). London: University College London.

MacRae, I., \& Furnham, A. (2014). High Potential: How to Spot Manage and Develop Talented People at Work. London: Bloomsbury.

McCall, M. W. (1997). High Flyers: Developing the Next Generation of Leaders. Boston, 
MA: Harvard Business School.

McCall, M. W. (2010). Recasting Leadership Development. Industrial and Organizational Psychology: Perspectives on Science and Practice, 3, 3-19. https://doi.org/10.1111/j.1754-9434.2009.01189.x

McClelland, D. C. (1965). Toward a Theory of Motive Acquisition. American Psychologist, 20, 321-333. https://doi.org/10.1037/h0022225

McCrae, R. R., \& Costa, P. T. (1985). Updating Norman's “Adequacy Taxonomy”: Intelligence and Personality Dimensions in Natural Language and in Questionnaires. Journal of Personality and Social Psychology, 49, 710.

https://doi.org/10.1037/0022-3514.49.3.710

McDonnell, A. (2011). Still Fighting the "War for Talent?" Bridging the Science versus Practice Gap. Journal of Business and Psychology, 26, 169-173. https://doi.org/10.1007/s10869-011-9220-y

McDonnell, A., Lamare, R., Gunnigle, P., \& Lavellem J. (2010). Developing Tomorrow's Leaders. Evidence of Global Talent Management in Multinational Enterprises. Journal of World Business, 45, 150-160. https://doi.org/10.1016/j.jwb.2009.09.015

Muck, P. M., Hell, B., \& Gosling, S. D. (2007). Construct Validation of a Short Five-Factor Model Instrument: A Self-Peer Study on the German Adaptation of the Ten-Item Personality Inventory (TIPI-G). European Journal of Psychological Assessment, 23, 166-175. https://doi.org/10.1027/1015-5759.23.3.166

Ng, T. W. H., Eby, L. T., Sorensen, K. L., \& Feldman, D. C. (2005). Predictors of Objective and Subjective Career Success: A Meta-Analysis. Personnel Psychology, 58, 367-408. https://doi.org/10.1111/j.1744-6570.2005.00515.x

Norton, P. J., \& Weiss, B. J. (2009). The Role of Courage on Behavioral Approach in a Fear-Eliciting Situation: A Proof-of-Concept Pilot Study. Journal of Anxiety Disorders, 23, 212-217. https://doi.org/10.1016/j.janxdis.2008.07.002

Silzer, R., \& Church, A. H. (2009). The Pearls and Perils of Identifying Potential. Industrial and Organizational Psychology, 2, 377-412.

https://doi.org/10.1111/j.1754-9434.2009.01163.x

Spreitzer, G. M., McCall, M. W., \& Mahoney, J. D. (1997). Early Identification of International Executive Potential. Journal of Applied Psychology, 82, 6-29.

https://doi.org/10.1037/0021-9010.82.1.6

Teodorescu, A., Furnham, A., \& Macrae, I. (2017). Trait Correlates of Success at Work. International Journal of Selection and Assessment, 25, 36-42. https://doi.org/10.1111/ijsa.12158

Thornton, B., Ryckman, R. M., \& Gold, J. A. (2011). Competitive Orientations and the Type A Behaviour Pattern. Psychology, 2, 411-415. https://doi.org/10.4236/psych.2011.25064

Wang, G., \& Netemeyer, R. G. (2002). The Effect of Job Autonomy, Customer Demandingness, and Trait Competitiveness on Salesperson Learning, Self-Efficacy and Performance. Journal of the Academic Study of Marketing Science, 30, 217-227.

https://doi.org/10.1177/0092070302303003

Wille, B., De Fruyt, D., \& Feys, M. (2013). Big Five Traits and Intrinsic Success in the New Career Era: A 15-Year Longitudinal Study on Employability and Work-Family Conflict. Applied Psychology: An International Review, 62, 124-156. https://doi.org/10.1111/j.1464-0597.2012.00516.x

Yang, Y., \& Green, S. B. (2011). Coefficient Alpha: A Reliability Coefficient for the 21st Century? Journal of Psychoeducational Assessment, 29, 377-392.

https://doi.org/10.1177/0734282911406668 